\title{
Use of Copper Microparticles in SEBS/PP Compounds. Part 1: Effects on Morphology, Thermal, Physical, Mechanical and Antibacterial Properties
}

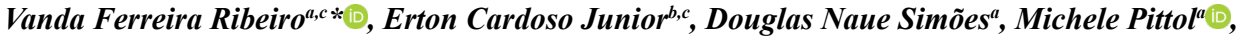 \\ Daiane Tomacheski ${ }^{a}$, Ruth Marlene Compomanes Santana ${ }^{c}$ \\ ${ }^{a}$ Softer Brasil Compostos Termoplásticos, Av. Edgar Hoffmeister, 275, CEP 93700-000, Campo Bom, \\ RS, Brasil \\ ${ }^{b}$ BRUTT Indústria Metalúrgica, R. Maurício Sirotsky Sobrinho, 31, Distrito Industrial, CEP 94930-370, \\ Cachoeirinha, RS, Brasil \\ ${ }^{c}$ Departamento de Engenharia de Materiais, Laboratório de Polímero - LAPOL, Universidade Federal \\ do Rio Grande do Sul, Av. Bento Gonçalves, 9500, Campos do Vale, CEP 90040-060, Porto Alegre, RS, \\ Brasil
}

Received: April 25, 2018; Revised: November 30, 2018; Accepted: January 17, 2019

\begin{abstract}
An alternative for producing thermoplastic elastomers (TPEs) with antibacterial properties is to add copper to the polymeric matrices. This study investigates the effects of the addition of copper microparticles on the morphological, thermal, physical and mechanical behavior and antibacterial properties of a blend composed by styrene-(ethylene-butylene)-styrene triblock copolymer (SEBS) and polypropylene (PP) homopolymer. The cooper microparticles used (commercial grade, produced by electrolytical process) were dispersed in a TPE matrix composed by SEBS/PP. Two bacterial species associated with infections (Escherichia coli and Staphylococcus aureus) were used in the antibacterial assays. The incorporation of copper microparticles in TPE matrix did not promote expressive changes in the thermal, physical and mechanical properties of the compounds. The findings from antibacterial assays showed a reduction of $99.99 \%$ in bacterial counts.
\end{abstract}

Keywords: SEBS, thermoplastic elastomers, copper microparticles, antibacterial.

\section{Introduction}

Compounds based on blends of styrene-(ethylenebutylene)-styrene (SEBS) and polypropylene (PP) represent an important type of thermoplastic elastomer (TPE) with applications in a range of rubber items, such as soft-touch surface on personal care products, tools, toys, housewares, automotive materials, among others. This kind of TPE replaces vulcanized rubber and polyvinyl chloride with the advantage of being fully recyclable, thus promoting less impact on the environment. In a typical production of SEBS/PP blends, the SEBS is mixed with PP to make stiffer materials and facilitate its processability ${ }^{1}$. Also, ingredients such as plasticizing oil, other polymers, fillers, and additives may be present in the compound formulation.

In various applications, the antimicrobial characteristic is desirable to avoid staining, bad smell, and deterioration. Infections caused by pathogenic microorganisms are a major concern and the use of polymers with antimicrobial properties gains an increasing interest from academic and industrial point of view ${ }^{2}$. Moreover, antimicrobial polymers are used as a strategy to prevent hospital-acquired infections ${ }^{3,4}$. Several publications report studies about the use of polymer/cooper formulations in antimicrobial applications ${ }^{3,5-12}$. However, except for previous work published by our research group on the use of copper nanoparticles ${ }^{13}$, publications based on SEBS/PP blends were not found in the literature. Compounds based on SEBS/PP do not have inherent biocidal properties. The usual form to obtain this characteristic is by adding an antimicrobial agent to polymers in the molten state. According to Jones ${ }^{14}$, antimicrobial polymers fit into two categories: organic (with biostatic properties) and inorganic (that combine biocidal and biostatic properties). Inorganic antimicrobials substances present metal ions as their active agent. They are stable in the processing conditions of thermoplastic polymers $\left(\sim 200^{\circ} \mathrm{C}\right)$ and, once incorporated in the compound, are continuously available during the life time of the particular finished product ${ }^{14,15}$. The metals commonly applied as biocides in polymers are silver, copper, and zinc ${ }^{3}$.

It is noteworthy the efficiency of copper against pathogenic bacteria, fungi, algae, and viruses. Previous studies with Gram-positive and Gram-negative have shown that the toxic mechanisms of copper rely on bacterial membrane damage, accumulation of copper ions in the cell ${ }^{16}$, and denaturation of nucleic acids ${ }^{17}$, which are also related to the broad-spectrum of actions including multidrug-resistant organisms ${ }^{18}$

Among the various methods of copper preparation, the powder produced from copper sulfate using electrolytic cells stands out as the main process. This method allows the obtainment of copper microparticles with high purity, besides specific size and shape (dendrites with a high surface area). 
The main industrial applications of electrolytic copper are electrical components, friction materials and sintering of parts.

This study investigates the effects of copper microparticles produced by a electrolytic process on the morphological, thermal, physical and mechanical behavior, besides the antibacterial properties of SEBS/PP compounds.

\section{Experimental}

\subsection{Materials}

The styrene-(ethylene-butylene)-styrene triblock copolymer (SEBS) was supplied by Kraton Polymers (styrene/rubber ratio of 30/70, molecular weight of 192.031 g.mol ${ }^{-1}$ and Mw/ $\mathrm{Mn}=1.36$ ) and polypropylene homopolymer was supplied by Braskem (melt flow index of $1.5 \mathrm{~g} / 10 \mathrm{~min}$ ). The oil plasticizer used was a white mineral oil with a viscosity of $105 \mathrm{cSt}$ (Raj Petro). Calcium carbonate with 325 mesh was used as mineral filler (Mocal). The commercial grade of copper microparticles with a density of $1.18 \mathrm{~g} / \mathrm{cm}^{3}$ and an average particle size of $46 \mu \mathrm{m}$ as average particle size (provided by Brutt Indústria Metalúrgica) was used as antibacterial agent.

\subsection{Preparation of the compounds}

All the compounds based in SEBS/PP/oil/calcite have a basic formulation, named $0 \% \mathrm{CuMP}$, as show in Table 1. Copper microparticles weight percentages were used on the basic formulations in $1 \%, 2 \%$ and $4 \%$ and this was the only variable in the compounds with copper, named $1 \%$ CuMP, 2\% CuMP and 4\% CuMP.

The materials were fabricated in a co-rotating double screw extruder (AX Plásticos, L/D ratio of 40 and $16 \mathrm{~mm}$ screw diameter) with a temperature profile from $150^{\circ} \mathrm{C}$ to $190^{\circ} \mathrm{C}$. The extrusion parameters were kept constant for all samples. TPE specimens were cut from a flat sheet (130 $\mathrm{mm} \times 130 \mathrm{~mm} \times 2 \mathrm{~mm}$ ) prepared in an injection molding machine (Haitian, PL860) at $190^{\circ} \mathrm{C}$. After preparation, the specimens were conditioned at $23 \pm 2{ }^{\circ} \mathrm{C}$ and $50 \pm 5 \%$ relative humidity for $72 \mathrm{~h}$ before testing.

\section{Methods}

\subsection{Thermal properties}

Differential Scanning Calorimetry (DSC) and Thermogravimetric (TGA) analysis were used to evaluate the thermal properties of the compounds. TGA analysis was

Table 1. Components of basic formulation of compounds ( $0 \% \mathrm{CuMP})$.

\begin{tabular}{ccccc}
\hline Ingredient & SEBS & PP & Oil & Calcite \\
\hline phr & 100 & 44 & 136 & 89
\end{tabular}

Note: phr (part per hundred of resin) performed in a TA Q500 (TA Instruments) under nitrogen flow from $20^{\circ} \mathrm{C}$ to $800^{\circ} \mathrm{C}$ (heating rate of $20^{\circ} \mathrm{C} / \mathrm{min}$ ) and sample weight of $\sim 11 \mathrm{mg}$. For DSC assay the samples were heated from $-30^{\circ} \mathrm{C}$ to $180^{\circ} \mathrm{C}$ at a heating rate of $10^{\circ} \mathrm{C} / \mathrm{min}$ in a DSC Q100 (TA Instruments) under nitrogen flow. Data were collected in the second heating to avoid interference of the thermal history of the compounds. The degree of crystallinity of the PP phase of the compounds, $X_{\mathrm{PP}}$, was calculated by applying equation $(1)^{1}$ :

$$
X_{P P}(\%)=\frac{\Delta H_{T P E}}{m_{P P} \times \Delta H_{P P}} \times 100
$$

Where $\Delta H_{\mathrm{TPE}}$ is the heat of crystallization of the PP phase, $m_{\mathrm{PP}}$ is the PP mass fraction in the compound and $\Delta H_{\mathrm{PP}}$ is the heat of crystallization per gram of $100 \%$ crystalline $\mathrm{PP}(209 \mathrm{~J} / \mathrm{g})$.

\subsection{Morphology}

Scanning Electron Microscopy (SEM) was performed to evaluate the morphology of TPE blends and copper microparticles. The TPE samples were torn at ambient temperature, placed in carbon tape, metalized with gold and analyzed with a SEM of field emission (SEM-FEG) (Auriga, Zeiss). Images were acquired with $30 \mathrm{kV}$ and working distance (WD) of $5.5 \mathrm{~mm}$. The copper microparticles images were analyzed in an equipment Inspect F50 (FEI), with $20 \mathrm{kV}$ and working distance (WD) of $11.9 \mathrm{~mm}$. Circular specimens of $25 \mathrm{~mm}$ in diameter and $2 \mathrm{~mm}$ thickness (cut from molten plates) were immersed for 72 hours in toluene to calculate the grade of co-continuity of the SEBS in the compounds, as proposed by Sengupta and Noordermeer. ${ }^{19}$

\subsection{Physical and mechanical properties}

The density was measured in accordance with ASTM D 792. Tensile properties were analyzed according to ASTM D 412C, using an Emic DL 2000 universal test machine. The determination of the hardness Shore A of the compounds was performed according to ASTM D 2240, using a Durometer Bareiss HPE-A, with a reading time of 3 seconds and resolution of 0.1 Shore A. At least five test specimens were tested to determine the result of each physical-mechanical test.

\subsection{Antibacterial activity}

The antibacterial efficiency of the loaded and non-loaded compounds were evaluated according to the Japan Industrial Standard (JIS) Z 2801: 2010. In this analysis, specimens of TPE blends ( $50 \mathrm{~mm} \times 50 \mathrm{~mm}$ ) were placed in a sterile Petri dish and $400 \mu \mathrm{L}$ of an solution with $2.5 \times 10^{5} \mathrm{CFU} / \mathrm{mL}$ of Escherichia coli ATCC 8739 (E. coli) or $2,7 \times 10^{5} \mathrm{CFU} / \mathrm{mL}$ of Staphylococcus aureus ATCC 6538 (S. aureus) suspension were inoculated on the specimen surface. All of them were incubated for $24 \mathrm{~h}$ at $35 \pm 1^{\circ} \mathrm{C}$. The difference between the number of colonies forming units (CFUs) at zero hour and 
after 24 hours of incubation was used to measure antibacterial activity (in percentage).

\section{Results and Discussion}

\subsection{Thermal properties}

The Figures 1 and 2 show, respectively, the TGA (thermogravimetric) and the DTG (derivative thermogravimetric) curves of individual components (SEBS, PP and oil plasticizer) and the compounds. As shown in Figure 1, the oil is the least thermally stable component, with a maximum rate of degradation at $369^{\circ} \mathrm{C}$, followed by SEBS $\left(448^{\circ} \mathrm{C}\right)$ and by $\mathrm{PP}\left(469^{\circ} \mathrm{C}\right)$.

As can be seen in Figure 2, the addition of CuMP did not promote expressive changes in the thermal degradation behavior of the compounds. In all samples three decomposition peaks were observed, the first and the second are related to the decomposition of oil and the third is related to the SEBS and PP. The higher thermal stability of the oil plasticizer when aggregated into the compound and its two-step decomposition can be attributed to the interaction with the other components of the formulation.

The presence of copper microparticles promoted a slight increase in thermal stability in the initial stage of degradation. This can be observed in the increase in temperature of the loss of $3 \%$ of mass $\left(\mathrm{T}_{3 \%}\right)$ shown in Table 2 . However, with the progress of the decomposition reaction kinetics, the behavior

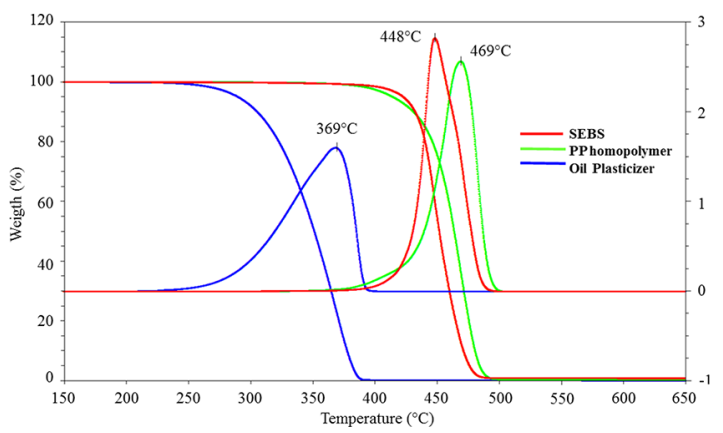

Figure 1. TGA and DTG curves of the individual components.

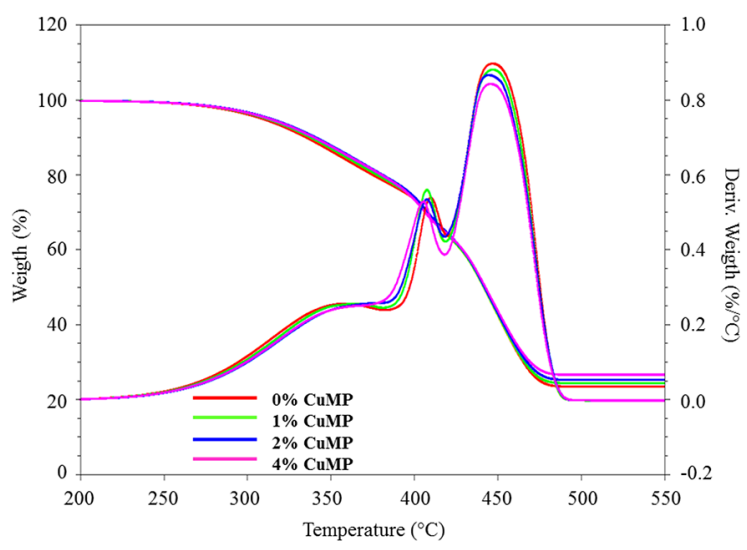

Figure 2. TGA and DTG curves of the compounds. tends to be similar in all compositions without significant variations in the final temperatures of each decomposition step. The action of the metal particles in polymers is dependent on the thermal conductivity of the particles, particle morphology, volume fraction, and dispersion in the polymer matrix ${ }^{20}$. Gorghiu et $\mathrm{al}^{21}$. investigated the effects of metals on thermal degradation of polyethylenes, and observed that, among the metals evaluated, copper was the most reactive, causing degradation with the shortest oxidation induction time and the highest oxidation rate. Based on various studies, copper presents high heat capacity and thermal conductivity and can encourage or retard, at different degrees, the thermal degradation of the organic phase $\mathrm{e}^{8,21,22,23}$.

The thermal properties obtained via DSC are presented in Table 3. The crystallization temperature (Tc) of PP phase reduced slightly with the increase in the copper content. This indicates that microparticles affect the crystallization process of the PP homopolymer. An effect that is corroborated by the lower degree of crystallinity $\left(\mathrm{X}_{\mathrm{PP}}\right)$ in the samples with $\mathrm{CuMP}$.

In the compounds with CuMP, fusion enthalpy $\left(\Delta \mathrm{H}_{\mathrm{f}}\right)$ of the PP phases decreases very little, from $11.7 \mathrm{~J} / \mathrm{g}(0 \%$ of $\mathrm{CuMP}$ ) to $10.8 \mathrm{~J} / \mathrm{g}$ (4\% of CuMP). No significant change was observed in the melting temperature of the PP phase. Through DSC it was not possible to detect the glass transition of PP phase in the compounds. This was already expected and can be explained by the fact that in ternary blends with SEBS the Tg of the PP-oil phase is a function of the total oil content. The literature has reported that the high temperature of transition of the PP rich phase disappears above $30 \mathrm{wt} \%$ oil $^{1}$.

Figure 3 shows the cooling curves of the compounds and the pure SEBS obtained by DSC. As seen, the cooling curves of the compounds show a small exothermic peak close to $-5^{\circ} \mathrm{C}$ and in pure SEBS this peak occurs at around $5^{\circ} \mathrm{C}$. The nature of these peaks is attributed to the crystallization of the ethylene blocks contained in the EB (ethylene butylene) phase of $\mathrm{SEBS}^{24}$. In the compounds, the oil is present in the olefinic EB blocks and it plasticizes this EB phase ${ }^{1}$ which explains the decrease in crystallization temperature compared to pure SEBS. An exothermic crystallization peak from the PP phase was observed in the compounds near to $107^{\circ} \mathrm{C}$. The temperature of crystallization of $\mathrm{PP}$ in the compounds was also lower than that observed in PP pure (see Table 2) which can be explained by the diluent character of the other components in the system, which delay the crystallization process of PP as reported in a previous study ${ }^{25}$.

\subsection{Morphology}

As can be seen in Figure 4, the CuMP used in this study presents a dendritic morphology. A dendrite is a hyper branched architecture formed by individual copper grains that are organized in a main stem and several lateral branches.

Through SEM images, it was possible to evaluate the dispersion of the CuMP in the compounds. Figures 5a, 5b and 
Table 2. TGA and DTG data of TPE compounds

\begin{tabular}{|c|c|c|c|c|c|c|c|}
\hline \multirow{2}{*}{ Sample } & \multicolumn{3}{|c|}{ TGA } & & \multicolumn{3}{|c|}{ DTG } \\
\hline & $\mathbf{T}_{3 \%}\left({ }^{\circ} \mathrm{C}\right)$ & $\mathrm{T}_{\text {end } 1^{\circ} \text { Step }}\left({ }^{\circ} \mathrm{C}\right)$ & $\mathbf{T}_{\text {end } 2^{\circ} \text { Step }}\left({ }^{\circ} \mathbf{C}\right)$ & $\mathbf{T}_{3^{\circ} \text { Step }}\left({ }^{\circ} \mathbf{C}\right)$ & TP1 $\left({ }^{\circ} \mathrm{C}\right)$ & TP2 $\left({ }^{\circ} \mathrm{C}\right)$ & TP3 $\left({ }^{\circ} \mathrm{C}\right)$ \\
\hline $0 \%$ CuMP & 294.8 & 382.5 & 419.8 & 472.8 & 357.4 & 409.9 & 447.0 \\
\hline 1\% CuMP & 297.1 & 381.5 & 418,8 & 473.0 & 364.3 & 407.6 & 446.9 \\
\hline 2\% CuMP & 299.0 & 380.8 & 417.8 & 473.3 & 375.4 & 407.7 & 444.6 \\
\hline $4 \%$ CuMP & 298.0 & 382.5 & 417.8 & 473.2 & 367.3 & 405.4 & 445.7 \\
\hline
\end{tabular}

Table 3. Melting (Tm) and Crystallization (Tc) Temperatures, Fusion, and Crystallization Enthalpy ( $\Delta \mathrm{Hf})$ and degree of crystallinity of PP phase (XPP) obtained by DSC.

\begin{tabular}{lccccc}
\hline Sample & $\mathbf{T}_{\mathbf{m}}\left({ }^{\circ} \mathbf{C}\right)$ & $\Delta \mathbf{H}_{\mathbf{f P P} \text { phase }}(\mathbf{J} / \mathbf{g})$ & $\mathbf{T}_{\mathbf{c} \text { PP phase }}\left({ }^{\circ} \mathbf{C}\right)$ & $\Delta \mathbf{H}_{\mathbf{c ~ P P ~ p h a s e ~}}(\mathbf{J} / \mathbf{g})$ & $\mathbf{X}_{\mathbf{P P} \text { phase }}(\%)$ \\
\hline \% \% CuMP & 152.6 & 11.7 & 108.4 & 13.2 & 47.2 \\
$1 \%$ CuMP & 152.2 & 11.4 & 107.4 & 12.6 & 46.2 \\
$2 \%$ CuMP & 152.4 & 10.9 & 106.8 & 12.4 & 44.5 \\
$4 \%$ CuMP & 152.2 & 10.8 & 106.7 & 12.1 & 45.3 \\
Pure PP & 166.8 & 88.8 & 113.4 & 90.6 & 42.5 \\
\hline
\end{tabular}

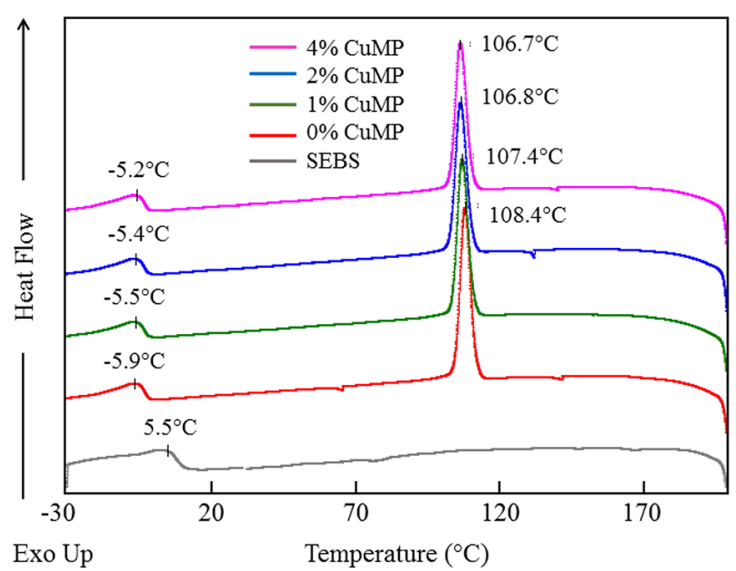

Figure 3. DSC curves of the compounds and the pure SEBS.

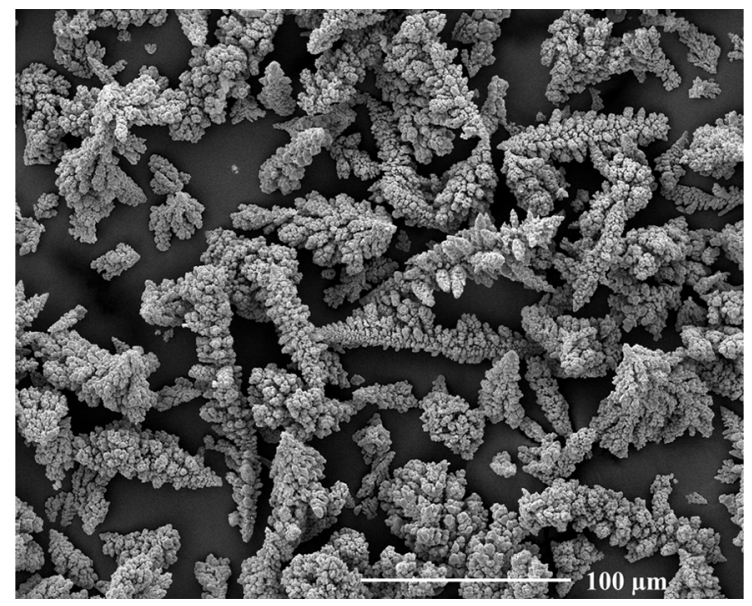

Figure 4. SEM images of copper microparticles (CuMP)

$5 \mathrm{c}$ show, respectively, the samples with $1 \%, 2 \%$ and $4 \%$ of CuMP and the Figure $5 \mathrm{~d}$ shows a dendrite when incorporated into the compound. Comparing the size of CuMP in nature and when incorporated into the compounds, the smaller size of the particles within the compound suggests that the extrusion processing broke those particles. The comminution of CuMP is desirable because the size of particles is a relevant parameter in the release mechanisms of metal ions ${ }^{7}$ that are a decisive factor in the antibacterial efficiency of the metal.

The microparticles are dispersed within the matrix of the analyzed samples. The co-rotating twin screw extruder used to produce the compounds has a configuration for SEBS/ PP blends and the screw design is suitable to promote the dispersion of the fillers. The configuration of the equipment and the others parameters generate shear conditions appropriate to wetting, the breakage of the agglomerates and separation of particles. According to $\mathrm{Palza}^{3}$, in a study of polymers with metal nanoparticles, the high viscosity of the matrix at the melt state can improve the dispersion of the particles. Similar observation have been reported by Kasaliwal et al. ${ }^{26}$, who stated that a high melt viscosity of the matrix would help to apply higher shear stresses on agglomerates leading to their faster dispersion.

Previous studies indicate that, in the concentrations of SEBS and PP evaluated in this study, both polymers might have co-continuous structures in the matrix, forming a normally referred to as physically cross-linked interpenetrating network ${ }^{9,27}$. The results of the extraction tests with toluene indicate that the presence of copper did not interfere in the morphology of the SEBS and PP phases. All the compositions featured a similar percentage of solubilization of phase SESB/oil, varying between $94.0 \%$ and $95.0 \%$, indicating that almost all SEBS was accessible from the surface of the samples. The Figure 6 shows that the specimens maintained the original shape. According to Ohlsson et al. ${ }^{16}$, if all of the SEBS can be extracted, the SEBS phase is continuous and if the polypropylene remains in one piece with the original shape, the PP phase is continuous. 

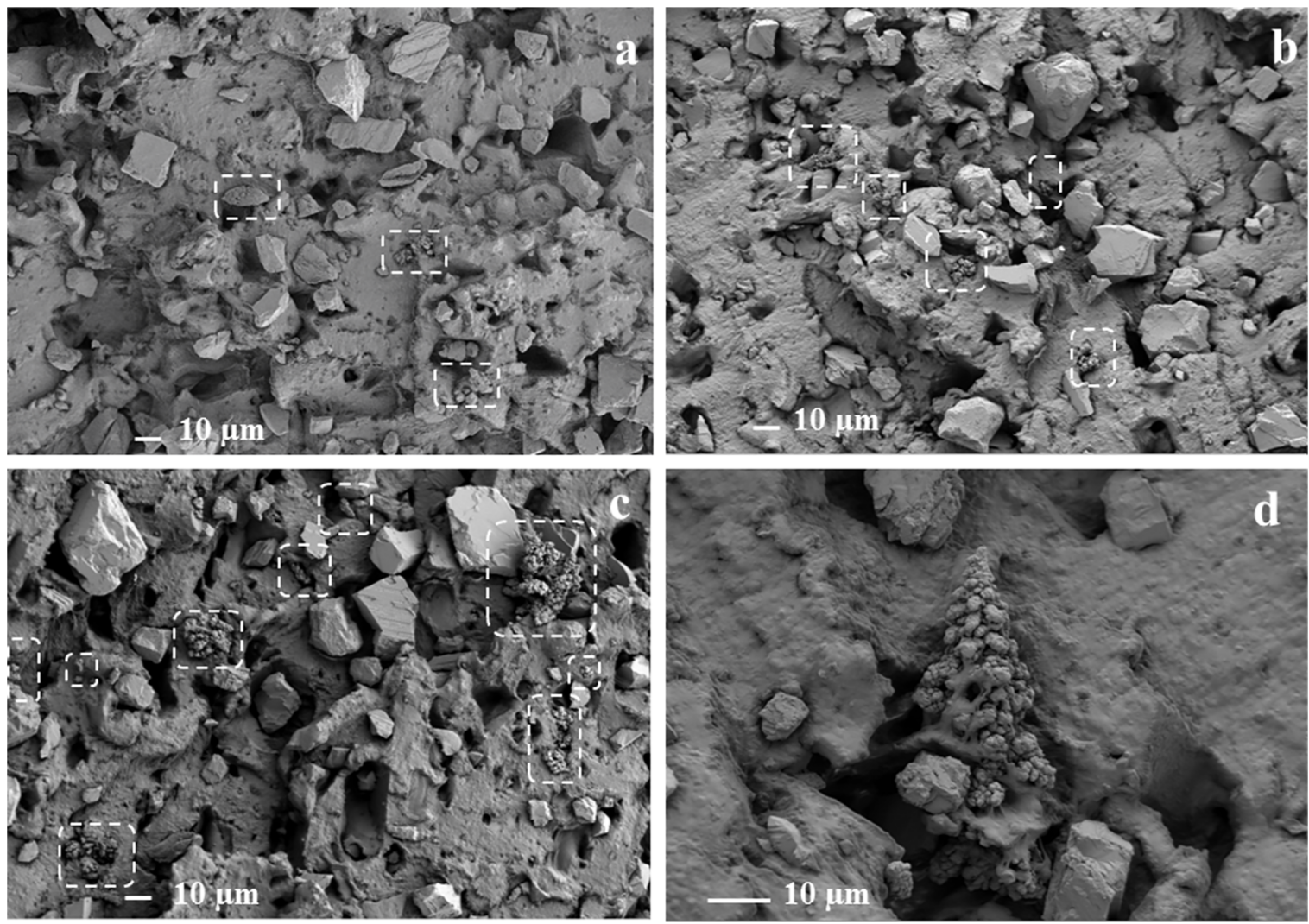

Figure 5. SEM images (a) Sample with 1\% copper microparticles, (b) Sample with $2 \%$ copper microparticles, (c) Sample with $4 \%$ copper microparticles and (d) dendrite incorporated into the compound.
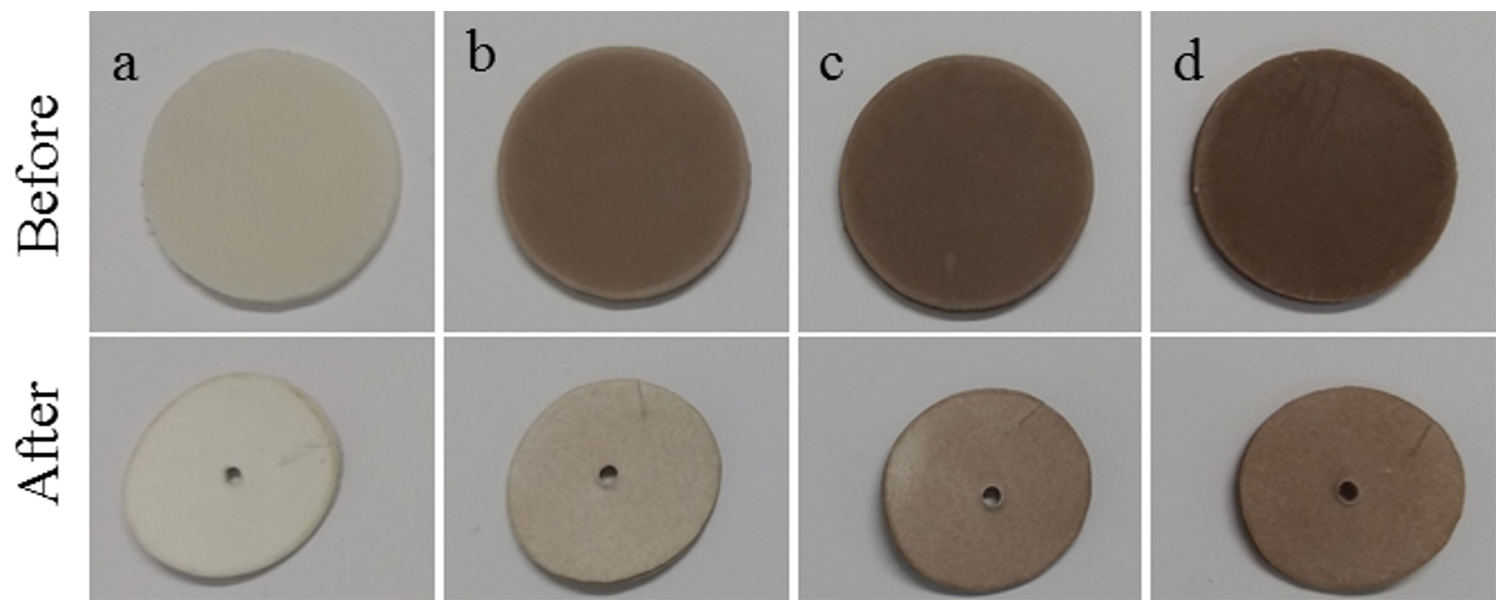

Figure 6. Images of the compounds before and after SEBS phase extraction. (a) $0 \% \mathrm{CuMP}$, (b) $1 \% \mathrm{CuMP}$, (c) $2 \% \mathrm{CuMP}$, (d) $4 \% \mathrm{CuMP}$

\subsection{Physical and mechanical properties}

The metal has a higher density than the other constituents of the formulation and the density increased by raising the copper content in the compounds, as observed in Figure 7.

The hardness and tensile properties are important to predict the mechanical performance of the compounds. Table 4 presents the results of these tests. A low reduction in the hardness of the compounds was observed with the presence of CuMP, but without a tendency. No significant

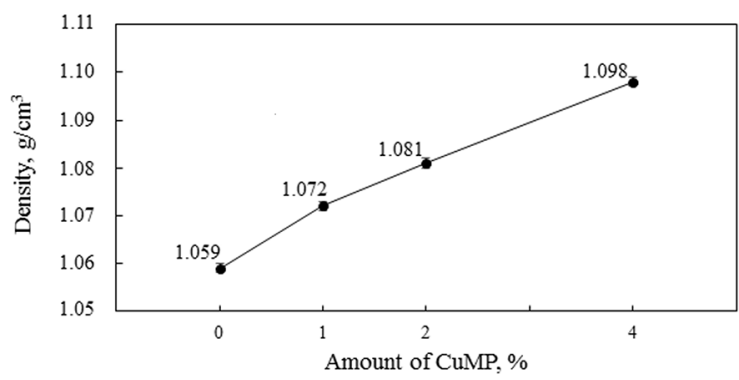

Figure 7. Density values of the compounds as a function of CuMP content 
Table 4. Hardness and tensile properties of TPE compounds

\begin{tabular}{lcccc}
\hline Sample & $\begin{array}{c}\text { Hardness } \\
\text { (Shore A) }\end{array}$ & $\begin{array}{c}\mathbf{1 0 0 \%} \text { Modulus } \\
(\mathbf{M P a})\end{array}$ & $\begin{array}{c}\text { Elongation at Break } \\
\text { (\%) }\end{array}$ & $\begin{array}{c}\text { Tensile Strength at } \\
\text { Break (MPa) }\end{array}$ \\
\hline $0 \%$ CuMP & $69.6 \pm 0.7$ & $1.86 \pm 0.01$ & $762 \pm 41$ & $9.06 \pm 1.14$ \\
$1 \%$ CuMP & $68.1 \pm 0.7$ & $1.80 \pm 0.01$ & $781 \pm 28$ & $8.97 \pm 0.96$ \\
$2 \%$ CuMP & $67.0 \pm 0.7$ & $1.90 \pm 0.04$ & $783 \pm 26$ & $9.10 \pm 0.78$ \\
$4 \%$ CuMP & $67.8 \pm 0.3$ & $1.85 \pm 0.03$ & $791 \pm 28$ & $9.03 \pm 1.04$ \\
\hline
\end{tabular}

variations in $100 \%$ modulus, elongation at break and tensile strength at break were observed with the addition of CuMP in compositions. The repeatability limit $(r)$ can be used to support or challenge that test results have been produced on the same material ${ }^{28}$ and the degree of variation in these results can be attributed to the uncertainty of the test method.

\subsection{Antibacterial assays}

The antibacterial activity of the compounds with the presence of copper microparticles was evaluated against the Gram-positive bacteria ( $S$. aureus) and the Gram-negative bacteria (E. coli). As seen in Table 5, there were significant differences in the bacterial reduction value between loaded and non-loaded compounds. The CuMP containing compounds presented an antibacterial action in all concentrations tested.

The most accepted mode of action of copper as an antimicrobial mentions the modification of bacterial membrane permeability $^{29}$ and the generation of reactive oxygen species ${ }^{30}$, which can damage bacterial proteins, lipids and nucleic acids. Sun at al. ${ }^{12}$ claim that, undoubtedly, killing bacteria process of copper started from the copper ions release. This confirms the one published by Delgado at al. ${ }^{31}$, which states that any material that can release $\mathrm{Cu}^{2+}$ will present antimicrobial behavior. The water and oxygen retained with in the polymer matrix promotes the metal biocide action ${ }^{3,7,10}$. The process takes place by the interaction with the surface of the particles promoting a corrosion reaction that releases copper ions from the copper particles. The low polarity of the polypropylene favors the diffusion of water molecules through its interconnected amorphous parts defining a percolated network. As the PP and the SEBS present a little distinction in polarity ${ }^{1}$, a similar behavior was expected in the elastomeric phase of the CuMP compounds. A previous study

Table 5. Antibacterial activity of the compounds

\begin{tabular}{lcccc}
\hline \multirow{2}{*}{ Sample } & \multicolumn{2}{c}{ E. coli } & \multicolumn{2}{c}{ S. aureus } \\
\cline { 2 - 5 } & $\begin{array}{c}\text { Reduction } \\
(\%)\end{array}$ & $\mathrm{R}$ & $\begin{array}{c}\text { Reduction } \\
(\%)\end{array}$ & $\mathrm{R}$ \\
\hline 0\% CuMP & $\begin{array}{c}\text { No } \\
\text { reduction }\end{array}$ & - & $\begin{array}{c}\text { No } \\
\text { reduction }\end{array}$ & - \\
1\% CuMP & 99.99 & 4.25 & 99.99 & 4.11 \\
2\% CuMP & 99.99 & 4.40 & 99.99 & 4.07 \\
4\% CuMP & 99.99 & 3.82 & 99.99 & 4.20 \\
\hline
\end{tabular}

NOTE: $\mathrm{R}$ - logarithmic reduction of bacterial population. Effective if $R \geq 2.0$. developed by our research group, with similar composition based on SEBS/PP, had already shown the effectiveness of copper nanoparticles against E.coli and $S$. aureus ${ }^{13}$.

\section{Conclusion}

Based on these results, it can be inferred that the metallic additive produced no significant variation in the morphological, thermal, physical and mechanical properties of the compounds. This is a positive factor for the final application of these compounds in a wide variety of products. The melt-extruded blend proved to be a suitable process to produce compounds containing metal microparticles well dispersed. The processing conditions promoted a break of dendrites with a desirable decrease in the size of the particles. Ultimately, electrolytic copper microparticles presented antibacterial activity against the most common bacteria associated with infections ( $E$. coli and $S$. aureus).

Further characterization is being developed to deepen understanding the effect of copper particles in compositions based on SEBS/PP. This information will improve the knowledge about the use of metallic particles in this type of TPE and its use in applications where antibacterial properties are a requirement.

\section{Acknowledgements}

The authors are grateful to Universidade Federal do Rio Grande do Sul (UFRGS) and Softer Brasil Compostos Termoplásticos LTDA. Funding. This work was supported by Financiadora de Estudos e Projetos (FINEP) [03.13.0280.00].

\section{References}

1. Sengers WGF, Wübbenhorst M, Picken JS, Gotsis AD. Distribution of oil in olefinic thermoplastic elastomer blends. Polymer. 2005;46(17):6391-6401. DOI: https://doi.org/10.1016/j. polymer.2005.04.094

2. Muñoz-Bonilla A, Fernández-García M. Polymeric materials with antimicrobial activity. Progress in Polymer Science. 2012;37(2):281-339. DOI: http://dx.doi.org/10.1016/j. progpolymsci.2011.08.005

3. Palza H. Antimicrobial Polymers with Metal Nonoparticles. International Journal of Molecular Science. 2015;16(1):20992116. DOI: http://dx.doi.org/10.3390/ijms16012099 
4. Palza H, Nuñez M, Bastías R, Delgado K. In situ antimicrobial behavior of materials with copper-based additives in a hospital environment. International Journal of Antimicrobial Agents. 2018;51(6):912917. DOI: https://doi.org/10.1016/j.ijantimicag.2018.02.007

5. Xue B, Jiang Y, Liu D. Preparation and Characterization of a Novel Anticorrosion Material: Cu/LLDPE Nanocomposites. Materials Transactions. 2011;52(1):96-101. DOI: https://doi.org/10.2320/ matertrans.M2010280

6. Cioffi N, Torsi L, Ditaranto N, Tantillo G, Ghibelli L, Sabbatini L, et al. Copper Nanoparticle/Polymer Composites with Antifungal and Bacteriostatic Properties. Chemistry of Materials. 2005;17(21):52555262. DOI: $10.1021 / \mathrm{cm} 0505244$

7. Palza H, Quijada R, Delgado K. Antimicrobial polymer composites with copper micro- and nanoparticles: Effect of particle size and polymer matrix. Journal of Bioactive and Compatible Polymers. 2015;30(4):366-380. DOI: https://doi.org/10.1177/0883911515578870

8. España-Sánchez BL, Rodríguez-González JA, González-Morones P, Neira-Velázquez MG, Franco-Bárcenas B, Anaya-Velázquez F, et al. Nanocomposites based on Polypropylene and Copper Nanoparticles: Preparation, Surface Activation by Plasma and Antibacterial Activity. Acta Universitaria. 2014;24(3):13-24. DOI: https://doi.org/10.15174/au.2014.526

9. Miranda C, Rodríguez-Llamazarez S, Castaño J, Mondaca MA. $\mathrm{Cu}$ nanoparticles/PVC Composites: Thermal, Rheological and Antibacterial Properties. Advances in Polymer Technology. 2018;37(3):937-942. DOI: https://doi.org/10.1002/adv.21740

10. Tamaio L, Azócar M, Kogan M, Riveros A, Páez M. Copper-polymer nanocomposites: An excellent and cost-effective biocide for use on antimicrobial surfaces. Materials Science and Engineering: $C$. 2016;69:1391-1409. DOI: https://doi.org/10.1016/j.msec.2016.08.041

11. Lomate GB, Dandi B, Mishra S. Development of antimicrobial LDPE/Cu nanocomposite food packaging film for extended shelf life of peda. Food Packaging and Shelf Life. 2018;16:211-219. https://doi.org/10.1016/j.fpsl.2018.04.001

12. Sun C, Li Y, Li Z, Su Q, Wang Y, Liu X. Durable and Washable Antibacterial Copper Nanoparticles Bridged by Surface Grafting Polymer Brushes on Cotton and Polymeric Materials. Journal of Nanomaterials. 2018;2018:6546193. DOI: https://doi. org $/ 10.1155 / 2018 / 6546193$

13. Ribeiro FR, Simões DN, Pittol M, Tomacheski D, Santana RMC. Effect of copper nanoparticles on the properties of SEBS/PP compounds. Polymer Testing. 2017;63:204-209. DOI: https://doi. org/10.1016/j.polymertesting.2017.07.033

14. Jones A. Killer Plastic: Antimicrobial Additives for Polymers. Plastics Engineering. 2008;64(8):34-40. DOI: https://doi. org/10.1002/j.1941-9635.2008.tb00362.x

15. D'Arcy N. Antimicrobials in plastics: a global review. Plastics Additives \& Compounding. 2001;3(12):12-15. DOI: https://doi. org/10.1016/S1464-391X(01)80328-7

16. Espírito Santo C, Lan EW, Elowsky GE, Quaranta D, Domaille DW, Chang SJ, et al. Bacterial killing by dry metallic copper surfaces. Applied and Environmental Microbiology. 2011;77(3):794-802. DOI: https://10.1128/AEM.01599-10
17. Warnes LS, Green SM, Michels HT, Keevil CW. Biocidal Efficacy Of Copper Alloys Against Pathogenic Enterococci Involves Degradation of Genomic and Plasmid DNAs. Applied and Environmental Microbiology. 2010;76(16):5390-5401. DOI: https://doi.org/10.1128/AEM.03050-09

18. Ingle AP, Duran N, Rai M. Bioactivity, mechanism of action, and cytotoxicity of copper-based nanoparticles: A review. Applied Microbiology and Biotechnology. 2014;98(3):1001-1009. DOI: https://doi.org/10.1007/s00253-013-5422-8

19. Sengupta P, Noordermeer JWM. Effects of Composition and Processing Conditions on Morphology and Properties of Thermoplastic Elastomer Blends of SEBS-PP-Oil and Dynamically Vulcanized EPDM-PP-oil. Journal of Elastomers and Plastics. 2004;36:307331. DOI: https://doi.org/10.1177/0095244304042668

20. Hashim AA, ed. Smart Nanoparticles Technology. Rijeka: Intech; 2012. Available from: www.issp.ac.ru/ebooks/books/open/ Smart_Nanoparticles_Technology.pdf. Access in: 20/08/2017.

21. Gorghiu LM, Jipa S, Zaharescu T, Setnescu R, Mihalcea I. The effect of metals on thermal degradation of polyethylenes. Polymer Degradation and Stability. 2004;84(1):7-11. DOI: https://doi. org/10.1016/S0141-3910(03)00265-9

22. Rusu M, Sofian N, Ibranescu C, Rusu D. Mechanical and thermal properties of copper-power-filled high density composites. Polymers and Polymer Composites. 2000;8(6):427-436.

23. Luyt AS, Molefi JA, Krump H. Thermal, mechanical and electrical properties of copper powder filled low-density and linear lowdensity polyethylene composites. Polymer Degradation and Stability. 2006;91(7):1629-1636. DOI: https://doi.org/10.1016/j. polymdegradstab.2005.09.014

24. Sierra CA, Galán C, Fatou JG, Parellada MD, Barrío JA. Thermal and mechanical properties of poly-(styrene-b-ethylene-co-butyleneb-styrene) triblock copolymers. Polymer. 1997;38(17):4325-4335. DOI: https://doi.org/10.1016/S0032-3861(96)01045-2

25. Tomacheski D, Pittol M, Ermel CE, Simões DN, Ribeiro VF, Santana RMC. Influence of processing conditions on the mechanical properties of SEBS/PP/oil blends. Polymer Bulletin. 2017;74(12):4841-4855. DOI: https://doi.org/10.1007/s00289-017-1994-2

26. Kasaliwal GR, Göldel A, Pötchke P, Heinrich G. Influences of polymer matrix melt viscosity and molecular weight on MWCNT agglomerate dispersion. Polymer. 2011;52(4):1027-1036. DOI: https://doi.org/10.1016/j.polymer.2011.01.007

27. Ohlsson B, Hassander H, Törnell B. Blends and thermoplastic interpenetrating polymer networks of polypropylene and polystyreneblock-poly(ethylene-stat-butylene)-block-polystyrene triblock copolymer. 1: Morphology and structure-related properties. Polymer Engineering and Science. 1996;36(4):501-510. DOI: https://doi. org/10.1002/pen.10436

28. Lau A. What Are Repeatability and Reproducibility. Part 1: AD02 Viewpoint for Laboratories. In: ASTM Standardizations News. West Conshohocken: ASTM International; 2009.

29. Espírito Santo C, Quaranta D, Grass G. Antimicrobial metallic copper surfaces kill Staphylococcus haemolyticus via membrane damage. Microbiology Open. 2012;1(1):46-52. DOI: https:// doi.org/10.1002/mbo3.2 
30. Chatterjee AK, Chakraborty R, Basu T. Mechanism of antibacterial activity of copper nanoparticles. Nanotechnology. 2014;25(13):135101. DOI: http://iopscience.iop.org/ article/10.1088/0957-4484/25/13/135101/meta
31. Delgado K, Quijada R, Palma R, Palza. Polypropylene with embedded copper metal or copper oxide nanoparticles as a novel plastic antimicrobial agent. Letters in Applied Microbiology. 2011;53(1):50-54. DOI: https://doi.org/10.1111/j.1472765X.2011.03069.X 